
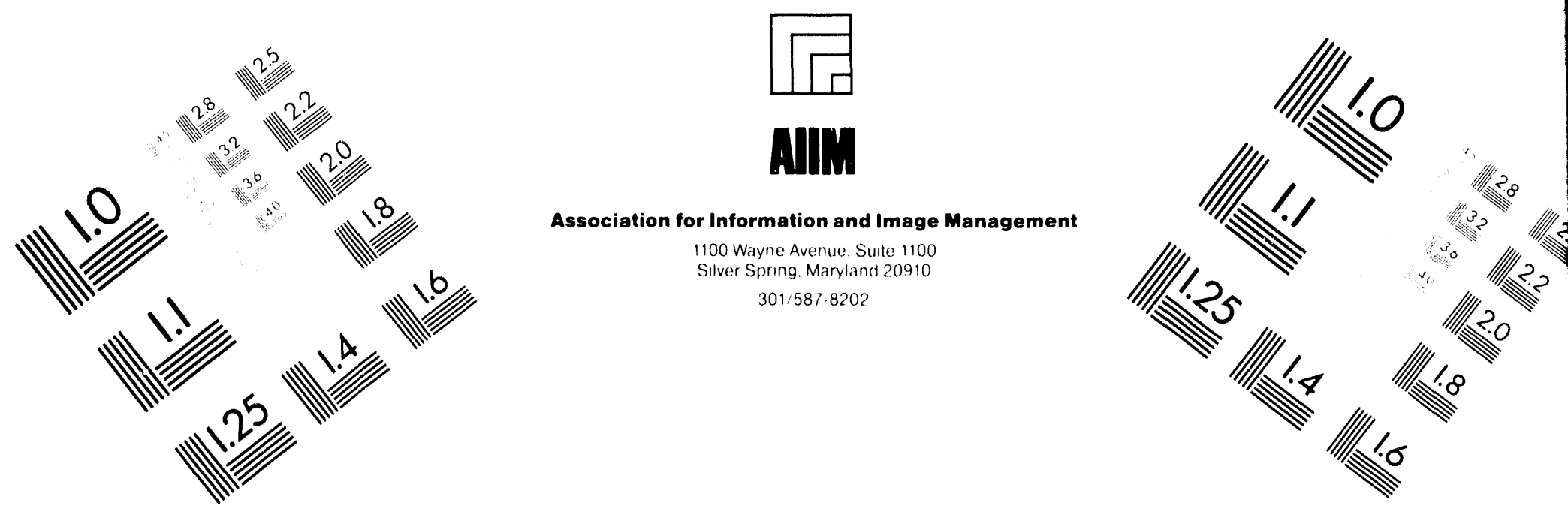

Centimeter

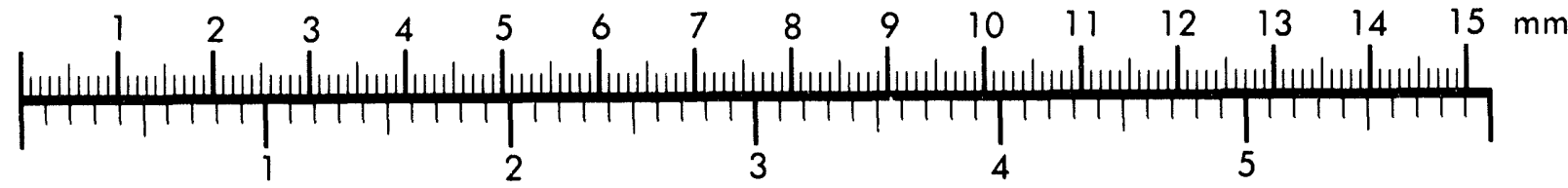

Inches
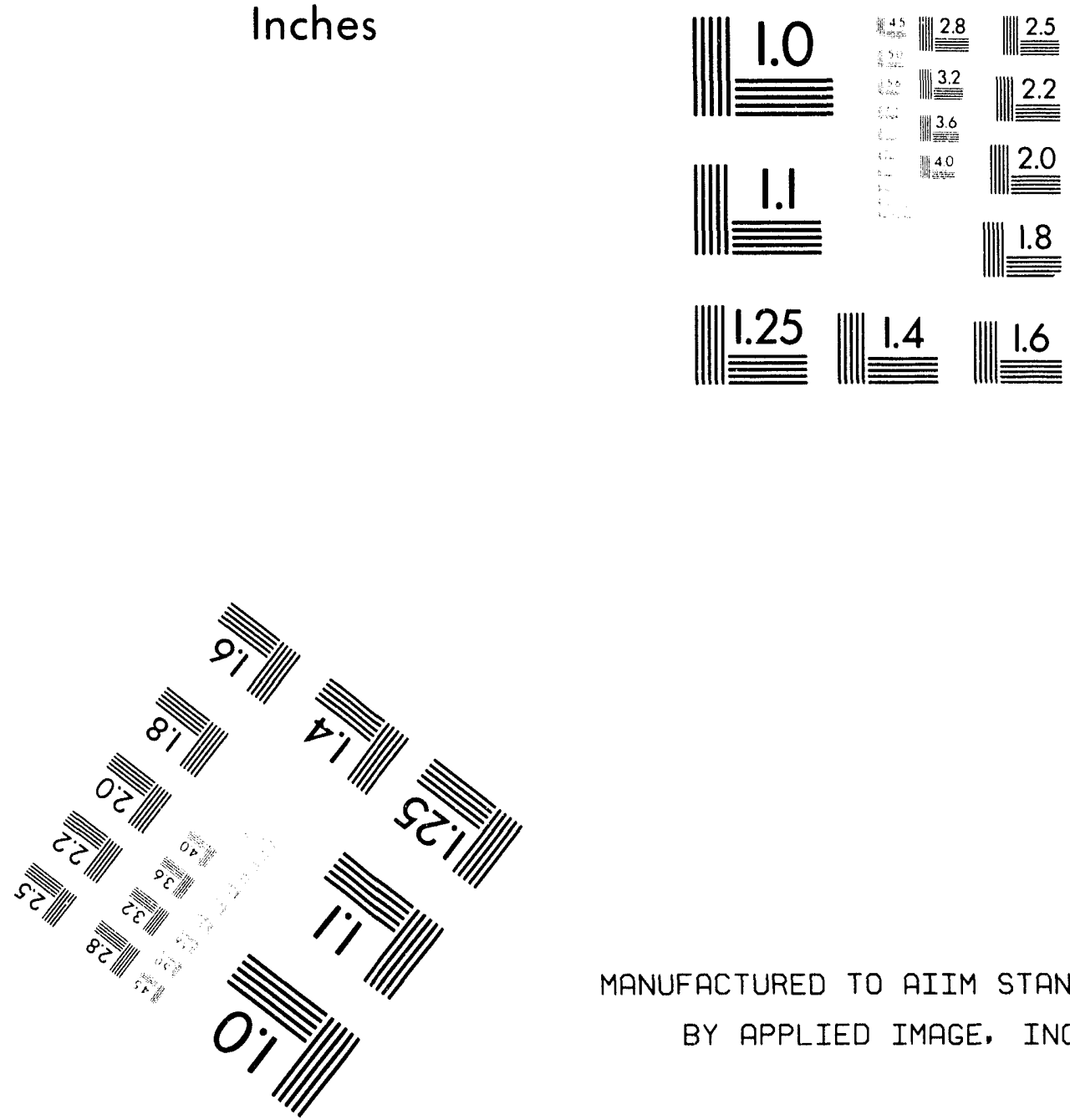

MANUFACTURED TO AIIM STANDARDS

BY APPLIED IMAGE, INC.

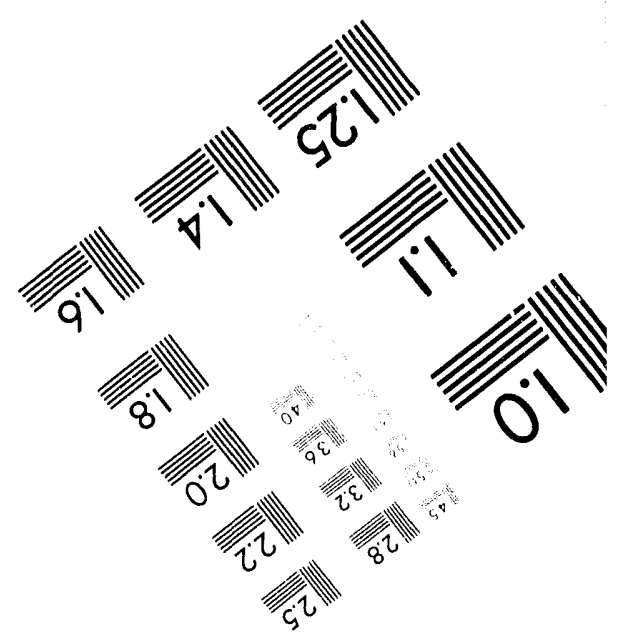



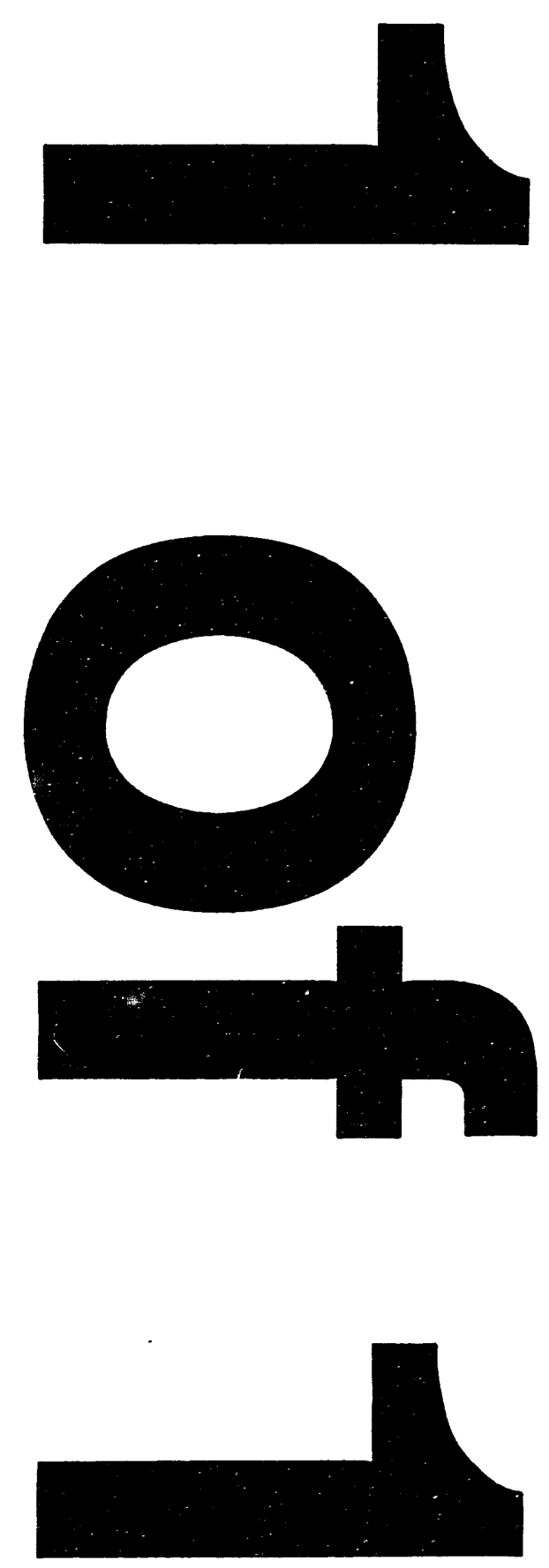


\section{RELEASE AUTHORIZATION}

Document Number: WHC-EP-0777

Document Title: $\quad$ VOC-Arid ID Guide to Preparation of Demonstration Documents

Release Date: $\quad 6 / 1 / 94$

$* * * * * * * * * * * * *$

This document was reviewed following the procedures described in WHC-CM-3-4 and is:

APPROVED FOR PUBLIC RELEASE

$* * * * * * * * * * * * *$

WHC Information Release Administration Specialis:

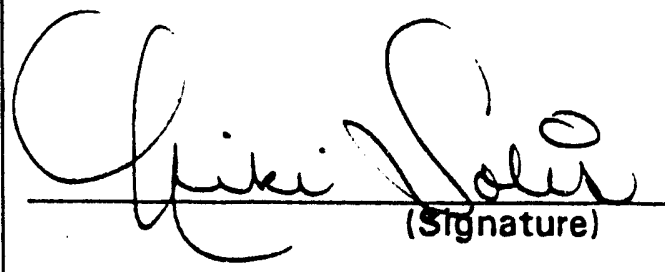

$6 / 1 / 94$

(Date) 


\section{VOC-Arid Integrated Demonstration Guide to Preparation of Demonstration Documents}

E. J. Jensen

T. M. Brouns

K. J. Koegler

G. H. McCabe

F. A. Morris

Date Published

June 1994

Prepared for the U.S. Department of Energy Office of Environmental Restoration and Waste Management

(2) Westinghouse Hantord Company P.O. Box 1970

Hanford Operations and Engineering Contractor for the

U.S. Department of Energy under Contract DE-AC06-87RL10930 


\title{
VOC-ARID ID GUIDE TO PREPARATION OF DEMONSTRATION DOCUMENTS
}

\author{
E. J. Jensen \\ T. M. Brouns \\ K. J. Koegler \\ G. H. McCabe \\ F. A. Morris
}

\begin{abstract}
This guide has been prepared by Demonstration Operations of the Volatile Organic Compound - Arid Integrated Demonstration. Its purpose is to describe demonstration documents, designate responsibilities for these documents, and to guide the Principal Investigator and others in their preparation. The main emphasis of this guide is to describe the documentation required of the Principal Investigator. However, it does cover some of the responsibilities of other members of the Volatile Organic Compound - Arid Integrated Demonstration team.

Jensen, E. J., T. M. Brouns, K. J. Koegler, G. H. McCabe, and F. A. Morris, 1994, VOC-Arid ID Guide to Preparation of Demonstration Documents, WHC-EP-0777, Westinghouse Hanford Company, Richland, WA.
\end{abstract}


WHC-EP - 0777

\section{CONTENTS}

1.0 INTRODUCTION . . . . . . . . . . . . . . . . . . . . . . . . . 1

1.1 BACKGROUND . . . . . . . . . . . . . . . . . . . . . 1

2.0 PROTECH PROFILE . . . . . . . . . . . . . . . . . . . . 4

3.0 DEMONSTRATION OBJECTIVES WORKSHEET . . . . . . . . . . . . . 4

4.0 ENVIRONMENTAL REGULATORY CHECKLIST . . . . . . . . . . . 4

5.0 CONCEPTUAL TEST PLAN . . . . . . . . . . . . . . . . . . 5

6.0 INTEGRATED TEST PLAN . . . . . . . . . . . . . . . . . . . . 5

7.0 SUMMARY OF DEMONSTRATION RESULTS AND DATA PACKAGE . . . 6

8.0 LESSONS LEARNED . . . . . . . . . . . . . . . . . . . . . 6

9.0 PERFORMANCE EVALUATION REPORTS . . . . . . . . . . . . 6

10.0 COST ANALYSIS REPORT . . . . . . . . . . . . . . . . . 7

11.0 STAKEHOLDER ACCEPTANCE ANALYSIS . . . . . . . . . . . . 7

12.0 TECHNOLOGY ACCEPTANCE REPORT . . . . . . . . . . . . . . 7

13.0 TECHNOLOGY EVALUATION REPORT . . . . . . . . . . . . . 8

\section{ATTACHMENTS :}

1. Protech Profile

2. Demonstration Objectives Worksheet

3. Environmental Regulatory Checklist

4. Conceptual Test Plan Template

5. Integrated Test Plan Template

6. Performance Evaluation Reports Template

\section{FIGURES :}

1. Schematic of Documentation Process Before Demonstration . . 2

2. Schematic of Documentation Process After Demonstration . . 3 
WHC - EP - 0777

\section{VOC-ARID INTEGRATED DEMONSTRATION GUIDE TO PREPARATION OF DEMONSTRATION DOCUMENTS}

\subsection{INTRODUCTION}

This guide has been prepared by Demonstration Operations of the Volatile Organic Compound - Arid Integrated Demonstration (VOC-Arid ID). Its purpose is to describe demonstration documents, designate responsibilities for these documents, and guide the Principal Investigator (PI) and others in their preparation. The main emphasis of this guide is to describe the documentation required of the PI. However, it does cover some of the responsibilities of other members of the VOC-Arid ID team.

Figures 1 and 2 illustrate the sequence of developing the documents described in this preparation guide. Figure 1 illustrates the documentation that occurs before the field demonstration, and Figure 2 illustrates the documentation that occurs after the field demonstration. The initials above each box in these schematics designates who is responsible for preparing that particular document. The initials that appear first indicate who has the lead. Refer to Figures 1 and 2 for clarification when reading this guide.

\subsection{BACRGROUND}

The VOC-Arid ID is one of several U.S. Department of Energy (DOE) integrated demonstrations designed to support the demonstration of emerging environmental management and restoration technologies. The principal objective of the vocArid ID is to identify, develop, and demonstrate new and innovative technologies for environmental restoration at arid or semiarid sites containing volatile organic compounds with or without associated contamination $(\mathrm{e} . \mathrm{g} .$, radionuclides and metals).

Demonstration Operations of the VOC-Arid ID is responsible for providing host site interface, site characterization, regulatory and Hanford compliance, and implementation of field demonstrations. Information requested by Demonstration Operations is used to plan and meet the requirements necessary to conduct field activities at all sites. Supplying complete and concise information as requested will allow Demonstration Operations to more effectively and efficiently meet the needs of the PI. Refer any questions regarding this document to Demonstration Operations [K. J. Koegler, ph. (509)376-2877, fax. (509) 376-6476]. 
WHC - EP - 0777

Figure 1. Schematic of Documentation Process Before Demonstration.

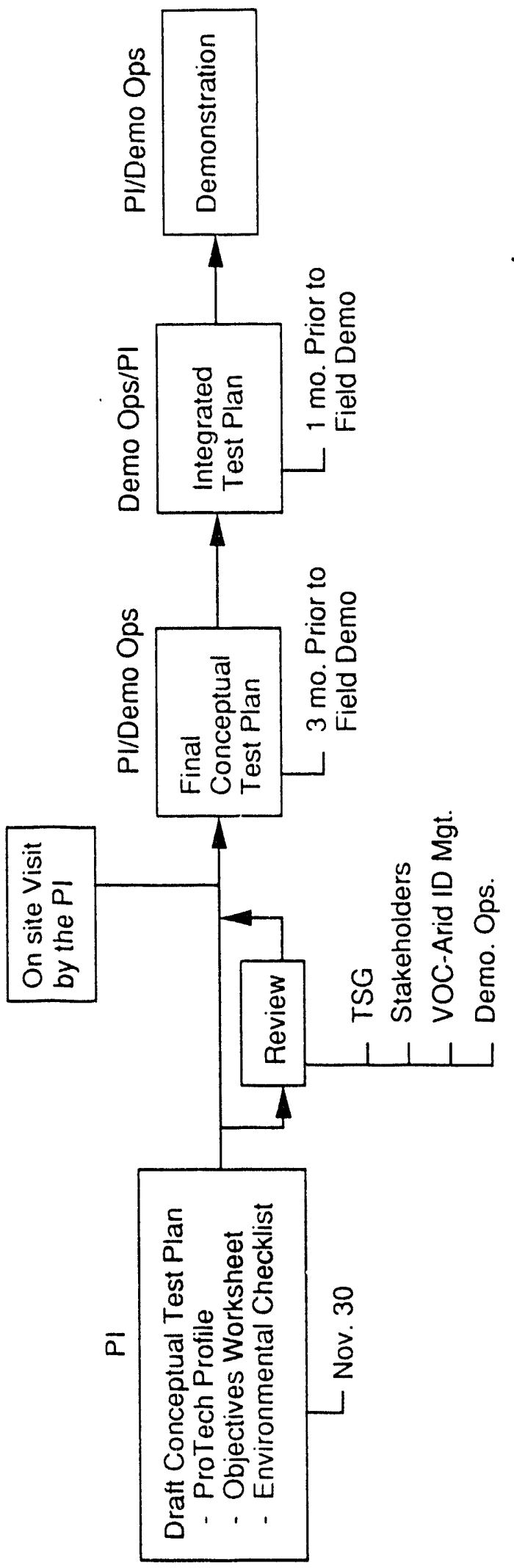




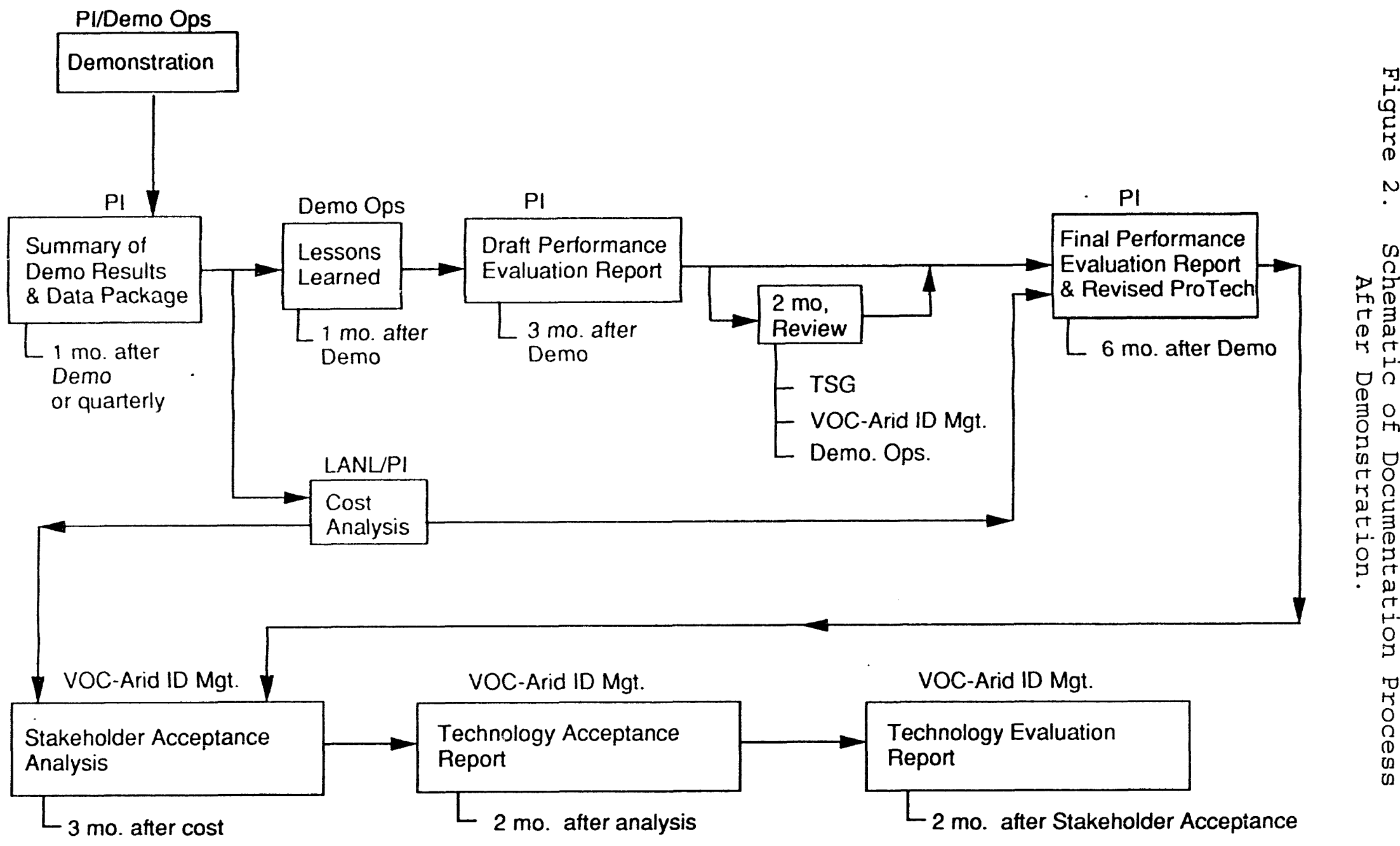


WHC - EP - 0777

\subsection{PROTECH PROFILE}

As a first step, the PI completes the ProTech profile in Attachment 1 of this guide. This profile provides information for ProTech, a computer-based communication system. ProTech is the basis for many of the stakeholder involvement activities conducted in support of the VOC-Arid ID. This computer tool was designed to facilitate public understanding of innovative technologies. The audience for ProTech includes individuals and groups who have a stake in a technology's deployment. These stakeholders include but are not limited to regulators, special interest groups, Native Americans, citizens in a community where an environmental technology may be used, and potential industrial co-developers and users of a technology. The information in the profile is based on the criteria that will be used to evaluate a technology. Some criteria are to be considered directly by the PI, and other criteria will require further evaluation by other components of the VOC-Arid ID (the Technology Acceptance Task of the VOC-Arid ID, the Cost Analysis Task at Los Alamos National Laboratory, the Technical support Groups [TSGs], etc.). When the profile is complete, it must be included in the Draft Conceptual Test Plan as Appendix $A$ and an electronic copy of the profile should be sent to the ProTech Point Person. Contact Demonstration operations for the location of the Point Person.

\subsection{DEMONSTRATION OBJECTIVES WORKSHEET}

The secord step for the PI is to fill out the Demonstration objectives Worksheet in Attachment 2 of this guide. The worksheet is intended to help the PI formulate objectives to guide field activities. When complete, the resulting objectives are to be transferred by the PI to the text in section 3.0 of the Draft Conceptual Test Plan and the worksheet is included as Appendix $B$ in the Draft Conceptual Test Plan.

\subsection{ENVIRONMENTAL REGULATORY CHECKLIST}

As a third step, the PI fills out the Environmental Regulatory Checklist in Attachment 3 of this guide. Regulatory experts of the VOC-Frid ID use this checklist to ensure compliance with applicable regulations. This allows the PI to concentrate on the demonstration instead of the regulations. After the checklist has been completed, the PI must include it in the Draft Conceptual Test Plan as Appendix D. 


\subsection{CONCEPTUAL TEST PLAN}

The purpose of the Conceptual Test Plan is for the PI to formulate demonstration objectives, provide information to initiate regulatory and Hanford compliance activities, and provide for review of plans for field activities.

The Conceptual Test Plan should follow the structure of the template in Attachment 4 as closely as possible. All sections of the template must be addressed, even if to identify that the PI does not believe that the section applies to their demonstration.

The Draft Conceptual Test Plan must be prepared by the PI and received by Demonstration Operations before November 30 of each year the technology is in the program.

The Draft Conceptual test plan will go through a review and comment cycle by the VOC-Arid ID management team, technical support groups, and stakeholders. The Draft Conceptual Test Plan will be called the Final Conceptual Test plan after the comments from this review cycle have been incorporated by the PI into the Draft Conceptual Test Plan and the plan has been accepted by Demonstration Operations.

The Final Conceptual Test Plan must be received by Demonstration Operations at least three months prior to demonstration.

\section{6 .0 INTEGRATED TEST PIAAN}

The Integrated Test Plan is produced by the Demonstration Operations project scientist or engineer with help from the PI. The Integrated Test Plan incorporates the Final Conceptual Test Plan to create an operations document for the Hanford Site. The Integrated Test Plan follows the template in Attachment 5 of this guide. An Integrated Test Plan may include demonstration of one or more technologies.

The Integrated Test Plan must be completed at least one month prior to the field demonstration. This allows enough time to complete the peer review, editing, and release (signature approval process) prior to the demonstration. The Integrated Test Plan must be released one week (five working days) before the field demonstration begins. All field demonstrations will be delayed to accommodate this schedule. 


\subsection{SUMRARY OF DEMONSTRATION RESULTS AND DATA PACKAGE}

To provide timely reporting and review of the data after the demonstration, the PI is responsible for writing a one- to twopage ieport summarizing the results of each demonstration. A data package of the measurements taken to measure the objectives must be included in this summary.

The summary must be received by Demonstration Operations within one month after the demonstration has been completed, or every quarter if the demonstration takes more than three months to complete.

\subsection{LESSONS LEARNED}

Lessons Learned is an informal letter report written by the Demonstration Operations project scientist or engineer in conjunction with the PI. It must be completed within one month after completion of the demonstration. This report should be brief (one to two pages).

The purpose of Lessons Learned is to provide Demonstration Operations with ideas and suggestions about how to do a better job of conducting demonstrations. Any problems encountered and resolutions made during preparation and execution of the demonstration should be identified. Things that went well should also be noted so that they can be repeated in the future.

\subsection{PERFORMANCE EVALUATION REPORTS}

The Performance Evaluation Report is prepared by the PI after the demonstration has been completed. It is designed to describe the technology that was demonstrated, what the technology is intended to do, and what the overall purpose and specific objectives of the demonstration were. In addition, it should describe where and when the technology was demonstrated, and summarize the performance results. Many of the sections in this report are the same as the Integrated Test Plan and may simply be copied to the Performance Evaluation Report.

Attachment 6 presents a template and more detailed description of how to prepare a Performance Evaluation Report.

At the time the Performance Evaluation Report is prepared, the ProTech Profile needs to be updated. A hard copy of the revised ProTech Profile should be attached as an appendix to the Performance Evaluation Report, and an electronic copy should be 
forwarded to the ProTech Point Person. Contact Demonstration operations for the location of the Point Person.

Demonstration Operations must receive a draft of this report within three months of the completion of the demonstration. Demonstration Operations will provide the PI with review comments within two months. The final report is due to Demonstration Operations one month later.

\subsection{COST ANALYSIS REPORT}

The cost analysis will be conducted by Los Alamos National Laboratory. The PI should include any information on costs in the ProTech profile under the cost criteria. These criteria are start-up cost, operations and maintenance cost, life cycle cost, and present worth cost. It is important to describe the range of uncertainty associated with each of the figures provided. One objective of the demonstration is to better estimate these costs through the data collected.

\subsection{STAKEHOLDER ACCEPTANCE ANALYSIS}

Analysis of stakeholder acceptance will be conducted by the Technology Acceptance Task Team at Battelle seattle. This team will use the ProTech profile to provide preliminary information stakeholders will use for technology evaluations. from which acceptance will be assessed. Focus groups and workshops with stakeholders (e.g., regulators, interest groups, and technologists) will be conducted on selected technologies to identify issues and concerns stakeholders may have about a technology. In addition, the Technology Acceptance Task Team will conduct interviews and presentations with a variety of stakeholders with the same objective. Some PIs will be asked to participate in some of these activities so that they can hear first hand what issues and concerns stakeholders may have. PIs are expected to consider this information and modify their demonstration test plan accordingly to enhance the acceptance of their technology.

\section{1:. 0 TECHNOLOGY ACCEPTANCE REPORT}

The Technology Acceptance Task Team will use the Performance Evaluation Report and Revised ProTech profile as the basis of follow-on analysis to determine stakeholder acceptance. 
Stakeholders will be interested in how their interests and concerno were addressed in the modified test plans. They will also evaluate the data and the degree to which large uncertainties were reduced. This information will be gathered by the Technology Acceptance Task Team and used by this team to produce the Technology Acceptance Report on particular technologies.

\subsection{TECENOLOGY EVALUATION REPORT}

The VOC-Arid ID Management Team will use three of the above documents to write the Technology Evaluation Report, which will be used to determine if a technology should be recommended for deployment. These documents are the Final Performance Evaluation Report, the Cost Analysis Report, and the Stakeholder Acceptance Report. The Summary Teclunology Evaluation Report will describe the advantages and Iimitations of the technology and make a recommendation to (1) deploy the technology, (2) modify and redemonstrate the technology, or (3) not deploy the techriology and discontinue its funding. 
WHC - EP - 0777

ATTACHMENT 1

ProTech Profile 


\section{PROTECH PROFILE}

This template should be used to prepare the initial ProTech profile for the Conceptual Test Plan and should be revised for the Performance Evaluation Report. Since the main audience for this profile is the general public, it needs to be written in terms that they can understand.

When the profile is complete, it must be included in the Draft Conceptual Test Plan as Appendix A, and an electronic copy of the profile should be sent to the ProTech Point Person. Contact Demonstration Operations for the location of the Point Person. After the demonstration is completed the PI will revise the ProTech Profile and include it as an appendix to the Performance Evaluation Report.

Technology Information Profile

1. Full Name of Technology:

2. Common Name of Technology:

3. Principal Investigator (and telephone number):

4. Affiliation:

5. Technology Category (Pick one of the following - Drilling, Characterization \& Monitoring, Retrieval, Treatment, or Containment/Disposal):

6. Developed by:

7. What is the need for the technology? (If this technology is part of a system of technologies, what is its role in the system and what is the need for the system?)

8. Technology Objectives

8.1. What are the objectives of this techrology? (for example, will this technology destroy volatile organic compounds [VOCs] in groundwater)?

8.2. What is the technology that is currently used for this. application (baseline technology)?

9. Process Description (Please describe the technology in terms that can be easily understood by interested members of the public. Include information on where the technology is applied -- in place or above ground -- what media the technology is used in - - soil, groundwater, air -- and what contaminants the technology targets): 
10. What is the status of the technology's development?

11. Summary of technology advantages (compared with the baseline technology-Is it faster, better, cheaper, safer?)

12. Summary of technology limitations (compared with the baseline technology):

13. Major technical challenges for the technology:

14. Technical Effectiveness

14.1. Performance Criteria

14.1.1. What contamination will remain after the technology is applied? (Will the mobility of the contamination be reduced? Will the volume be reduced? Will the contaminant be less toxic? This criterion applies primarily to retrieval treatment technologies.)

14.2. Process Waste

14.2.1. What process waste (secondary waste) does the technology produce? (Is the secondary waste mobile? What is its volume? What hazards are associated with the secondary waste? Can it be recycled?)

14.2.2. Describe the treatment or storage needed for the secondary waste and its availability:

14.2.3. Describe the requirements for decontamination or decommissioning of equipment.

14.2.4. How must the secondary waste be disposed of? Is disposal available?

14.3. Practicality

14.3.1. What future cleanup options are precluded by this technology? (Applies primarily to treatment technologies)

14.3.2. How reliable is the technology? (Please address potential breakdowns, effectiveness, and sensitivity to operating conditions)

14.3.3. If the technology fails, how are the effects of the failure controlled?

14.3.4. How easy is the technology to use? (Please describe the level of skills and training required to use the technology.) 
14.3.5. What infrastructure (buildings, power sources, personnel) is needed to support the technology?

14.3.6. How versatile is the technology? (That is, can it be applied to other types of contamination, in other media, or at other locations?)

14.3.7. Describe the technology's compatibility with other elements of the system? (Please in lude a general description of the system that the technology is part of.)

14.3.8. Can the technology be procured "off-the-shelf?" (Is it an innovative use of an existing technology?) Which components are available and which must be developed?

14.3.9. How difficult is the technology equipment to maintain? (Please include information on frequency as will as ease of maintenance. Also describe the level of skill or training required to maintain the technology.)

14.3.10. What equipment safety measures (such as automatic shutdown devices) are needed and in place to protect workers and the public?

14.3.11. How will the technology's performance be monitored?

14.3.12. What are the scale-up issues and how are they being addressed?

14.4. Describe the technology's ability to function as intended. (Does the technology work as intended? If not, describe functional problems.)

15. Cost (Please include assumptions on which you base your estimates.)

15.1. What is the start-up cost of the technology (including development costs, procurement and construction, permitting, and other costs necessary to begin operation)?

15.2. What are the operations and maintenance costs of the technology?

15.3. What are the life cycle costs of the technology (including facility capital cost; startup, operation, and maintenance; decommissioning, regulatory, or institutional oversight; and future liability)? 
15.4. What are the present worth costs of the technoloryy?

16. Time

16.1. When will the technology be available for commercial use or use at other sites?

16.2. What is the speed or rate of the technology? (Please use metrics)

16.3. At the speed or rate identified in 16.2 ., what is the total time required for the technology to achieve its objectives?

17. Environmental Safety and Health

17.1. Worker Safety

17.1.1. What potential is there for workers to be exposed to hazardous materials and/or other hazards? Describe those materials and hazards:

17.1.2. What are the physical requirements for workers?

17.1.3. How many people are required to operate the technology?

17.2. Public Health and Safety

17.2.1. What is the technology's history of accidents? (Has there been a history of accidents and, if so, of what nature?)

17.2.2. Does this technology produce routine releases of contaminants?

17.2.3. Are there potential impacts from transportation of equipment, samples, waste, or other materials associated with the technology?

18. Environmental Impacts

18.1. What impact will this technology have on the ecology of the area (for example, wildlife, vegetation, air, water, soil, or people)?

18.2. What aesthetic impacts does the technology have (for example, visual impacts, noise)?

18.3. What, if any, are the intense or exceptionally high use of natural resources used in the technology's development, manufacture, or operation? (Address energy resources in 18.4.) 
18.4. What are the technology's energy requirements?

(Use metrics)

19. Socio-Political Interests

19.1. Fublic Perception

19.1.1. What is the reputation of the technology's developer and/or user? (Principal investigators: this is a point of discussion for stakeholders; do not answer.)

19.1.2. How familiar is the technology to the public?

19.1.3. How easy is the technology to explain to the public?

19.2. Tribal Rights/Future Land Use

19.2.1. How will the technology affect future unrestricted use of land and water?

19.2.2 What ongoing control and monitoring are technically required and, if necessary, what is the reliability of long-term control?

20. Socio-Economic Interests

20.1. What are the potential economic impacts of this technology? (For example, what are the effects on the economic base of the community? Are there infrastructure requirements?)

20.2. How will the technology affect labor force demands?

21. Regulatory Objectives

21.1. Describe the technology's compatibility with cleanup milestones:

21.2. How familiar are regulators with this or a similar technology?

21.3. What is the technology's regulatory track record?

21.4. How does the technology comply with applicable $r \in g u l a t i o n s ?$

22. Industrial Partnerships

22.1. What is the name of the industrial partner?

22.2. What is the rationale for this partnership? 
22.3. What is the contract mechanism?

22.4. Are there other potential partners?

22.5. Are there potential international partners?

23. Intellectual Property

23.1. Who owns the patent for this technology?

23.2. Are there other patent owners?

23.3. Is there a patent number for this technology?

24. Background Information

24.1. What is the biackground of this technology? (Where did the idea come from? Who else is doing similar work? What have the results been to date? What is the most significant competitor to this technology?)

25. References:

Information reviewed for accuracy (Principal Investigator's initials): 
WHC - EP - 0777

:

ATTACHMENT 2

Demonstration Objectives Worksheet 


\section{DEMONSTRATION OBJECTIVES WORKSHEET}

The following worksheet is to be completed by the PI in applying the evaluation criteria to generate demonstration objectives for VOC-Arid ID demonstrations. The objectives identify what you intend to accomplish during the demonstration. The objectives must be clear and concise. After completing the worksheet

transfer the objectives to section 3.1 of the Conceptual Test Pan. The Conceptual Test Plan Template (Attachment 4) describes how this is to be accomplished. When this is complete, include the objectives worksheet in Appendix $B$ of the Conceptual Test Plan.

For each evaluation criterion, the worksheet:

1) indicates which of the three major technology types the criterion is relevant to (Remediation technologies [i.e., retrieval, treatment, or containment/disposal]; Drilling technologies; and/or Characterization and Monitoring technologies);

2) provides a reference to the corresponding CERCLA remedy selection criterion and ProTech element;

3 ) indicates whether the criterion shouid be considered directly by the PI in formulating demonstration objectives, or whether the criterion will require further evaluation by other components of the VOC-Arid T.D Team le.g., the Technology Acceptance Task of the VOC-Arid ID, the Cost Analysis Task at LANL, the TSGs, et:c.); and

4) provides a checklist for determining whether the criterion will in fact be translated irito a demonstration objective that will shape the data-gathering and analysis activities of the demonstration.

The 15 criteria represent broad categories of concern. Within each criterion there may be several sub-criteria relevant to the formulation of demonstration objectives. These sub-criteria correspond to each bulleted option under Identification of Demonstration objectives below. The PI should consider which of these entries should be included as a demonstration objective for the particular technology being demonstrated. In the spaces immediately following, the PI should either enter the corresponding demonstration objective or briefly explain why this item does not result in a demonstration objective.

In the course of completing this worksheet, the PI may find that several demonstration objectives arise from one criterion or alternatively that one demonstration objective may be able to address several criteria. In the first case, the PI should simply enter the multiple demonstration objectives under that criterion; in the second case, the PI should enter the demonstration objective under each applicable criterion and also provide a cross-reference to the other criteria to which the demonstration objective applies. 


\section{Criterion 1. Technology Performance: Remaining Contamination}

Applicalple to: Remediation

Source: EPA CERCLA Criteria \#2, 3 and 4; ProTech Element \#14

Should it be considered by PI in formulating demonstration objectives?: YES

This criterion focuses on the degree to which a remediation technology treats the contamination, and thereby leads to a reduction in environmental risk. A technology's performance with respect to the criterion is evaluated in terms of the characteristics of any contamination remaining after treatment. These characteristics can clearly be measured directly as part of a demonstration and thus should be used in setting demonstration objectives for remediation technologies.

Identification of demonstration objectives

- Demonstration objective regarding the type and amount of contaminated materials destroved or treated

Included, as follows:

Not included, because:

- Demonstration objective regarding the type and amount of residual contamination remaining after treatment

Included, as follows:

Not included, because:

- Demonstration objective regarding the degree of reduction of mobility of the contaminants

Included, as follows:

Not included, because:

- Demonstration objective regarding the degree of reduction of volume of the contaminants

Included, as follows:

Not included, because:

- Demonstration objective regarding the degree of reduction of toxicity of the contaminants

Included, as follows:

Not included, because: 
- Demonstration objective regarding the degree to which treatment is irreversible

Included, as follows:

Not included, because:

\section{Criterion 2. Technology Performance: Process Waste}

Applicable to: Remediation, Drilling, Characterization and Monitoring

Source: EPA CERCLA Criteria \#2, 3, and 4; ProTech Element \#14

Should it be considered by PI in formulating demonstration objectives? : YES

This criterion focuses on the degree to which the technology being demonstrated creates process wastes or other emissions and the extent to which these wastes or emissions can be effectively managed.

Identification of demonstration objectives

- Demonstration objective regarding the type and amount of process waste or emissions generated by treatment (including waste mobility, volume, hazard, recyclability)

Included, as follows:

Not included, because:

- Demonstration objective regarding whether and how waste or emissions can be effectively managed (through specified treatment, storage, and disposal of the waste or emissions)

Included, as follows:

Not included, because:

- Demonstration objective regarding whether and how any necessary decontamination/decommissioning can be effectively accomplished

Included, as follows:

Not included, because:

Criterion 3. Implementability and Practicality of Technology

Applicable to: Remediation, Drilling, Characterization and Monitoring 
Source: EPA CERCLA Criterion \#6; ProTech Element \#14

Should it be considered by PI in formulating demonstration objectives? : YES

This criterion covers issues related to whether the technology is easy to use and practical. It relates both to the technical reliability of the technology and to whether its use is lugistically feasible.

Identification of demonstration objectives

- Demonstration objective regarding whether the technology forecloses other kinds of cleanup options

Included, as follows:

Not included, because:

- Demonstration objective regarding the reliability of the technology and the nature and extent of any operational problems

Included, as follows:

Not included, because:

- Demonstration objective regarding whether, if the technology fails, it is possible to control the failure easily and rapidly

Included, as follows:

Not included, because:

- Demonstration objective regarding the technology's ease of use

Included, as follows:

Not included, because:

- Demonstration objective regarding the kind of infrastructure required for the technology (e.g., buildings, power sources, materials, personnel, specialists)

Included, as follows:

Not included, because:

- Demonstration objective regarding the versatility of the technology in addressing other types of contamination, in other media, in other locations, etc.: i.e., any limits on operating conditions 
Included, as follows:

Not included, because:

- Demonstration objective regarding the compatibility of the technology with other elements of the remediation system

Included, as follows:

Not included, because:

- Demonstration objective regarding the ease of procuring the technology or critical components (i.e., can it be procured off-the-shelf, etc.)

Included, as follows:

Not included, because:

- Demonstration objective regarding the ease and frequency of required maintenance

Included, as follows:

Not inclucied, because:

- Demonstration objective regarding the kind of safety measures required for the technology

Included, as follows:

Not included, because:

- Demonstration objective regarding the ease of monitoring the performance of the technology

Included, as follows:

Not included, because:

Criterion 4. Does the Technology Function as Intended?

Applicable to: Remediation, Drilling, Characterization and Monitoring

Source: EPA CERCLA Criterion \#6; ProTech Element \#14

Should it be considered by PI in formulating demonstration objectives?: YES

This criterion provides a general assessment of how well the technology performs its intended function. This is a basic standard for acceptability of the technology that must be 
included as one or more demonstration objectives, unless the test plan is for a preliminary demonstration to address particular issues of concern before full demonstration.

Identification of demonstration objectives

Demonstration objectives regarding how well the technology performs its intended functions

Included, as follows:

Not included, because:

Criterion 5. Cost

Applicable to: Remediation, Drilling, Characterization and Monitoring

Source: EPA CERCLA Criterion \#7; ProTech Elements \#15

Should it be considered by PI in formulating demonstration objectives?: YES

Although IANL will fully evaluate cost, the PI should determine (in conjunction with LANL) what data should be collected during the demonstration to support this assessment.

Identification of demonstration objectives

- Demonstration objective regarding capital costs

Included, as follows:

Not included, because:

- Demonstration objective regarding operating and maintenance costs

Included, as follows:

Not included, because:

- Demonstration objective regarding life-cycle cost

Included, as follows:

Not included, because:

- Demonstration objective regarding present worth cost Included, as follows:

Not included, because: 


\section{Criterion 6. Time}

Applicable to: Remediation, Drilling, Characterization and Monitoring

Source: EPA CERCLA Criterion \#5; ProTech Element \#16

Should it be considered by PI in formulating demonstration objectives? : YES

This criterion addresses the timeliness of the technology--both in terms of its availability (i.e., how soon would it be available for full scale use) and in terms of its operation (i.e., how quickly will it perform its task).

Identification of demonstration objectives

- Demonstration objective regarding how soon the technology will become available for fullscale deployment

Included, as follows:

Not included, because:

- Demonstration objective regarding the speed or rate of technology performance

Included, as follows:

Not included, because:

- Demonstration objective regarding the time required for the technology to complete its task (i.e., remediation for remediation technologies, analysis for characterization technologies, etc.)

Included, as follows:

Not included, because:

\section{Criterion 7. Worker Health and Safety}

Applicable to: Remediation, Drilling, Characterization and Monitoring

Source: EPA CERCLA Criterion \#5; ProTech Element \#17

Should it be considered by PI in formulating demonstration objectives? : YES

This criterion addresses the worker health and safety issues posed by use of the technology. 


\section{Identification of demonstration objectives}

- Demonstration objective regarding the nature and extent of worker exposure to hazardous materials or other hazards

Included, as follows:

Not included, because:

- Demonstration objective regarding the nature and extent of physical requirements for using the technology

Included, as follows:

Not included, because:

- Demonstration objective regarding how many people are required to operate the technology

Included, as follows:

Not included, because:

\section{Criterion 8. Public Health and Safety}

Applicable to: Remediation, Drilling, Characterization and Monitoring

Source: EPA CERCLA Criterion \#5; ProTech Information Element $\# 17.2$

Should it be considered by PI in formulating demonstration objectives? : YES

This criterion addresses general issues of community health and safely posed by use of the technology.

Identification of demonstration objectives

- Demonstration objective regarding the likely number and severity of accidents that might arise from use of the technology

Included, as follows:

Not included, because:

- Demonstration objective regarding the potential impact of routine releases of contaminates to air, ground or water pathways from using this technology

Included, as follows: 
Not included, because:

- Demonstration objective regarding the potential impacts of transporting equipment, samples, or other materials associated with use of this technology

Included, as follows:

Not included, because:

Criterion 9. Environmental Impacts

Applicable to: Remediation, Drilling, Characterization and Monitoring

Source: EPA CERCLA Criterion \#5; ProTech Element \#18

Should it be considered by PI in formulating demonstration objectives? : YES

This criterion addresses the general impacts of the technology on the environment.

Identification of demonstration objectives

- Demonstration objective regarding the ecological impacts of using the technology

Included, as follows:

Not included, because:

- Demonstration objective regarding the aesthetic impacts of using the technology

Included, as follows:

Not included, because:

- Demonstration objective regarding the natural resources required in the development, manufacture, or operation of the technology

Included, as follows:

Not included, because:

- Demonstration objective regarding the energy demands of the technology

Included, as follows:

Not included, because: 
WHC - EP - 0777

Criterion 10. Technology Reputation/Familiarity to Public

Applicable to: Remediation, Drilling, Characterization and Monitoring

Source: ProTech Element \#19

Should it be considered by PI in formuloting demonstration objectives?: Probably not. Performance with respect to this criterion is generally not directly demonstrable through a field demonstration.

This criterion relates to the general public perception of the technology. It addresses questions about both the reputation of the technology or technology developers, and about public familiarity with the technology. This criterion is most appropriately addressed by the ID Technology Acceptance Team or the TSGs. However, the PI might want to consider how to design or conduct the demonstration to support this criterion.

\section{Criterion 11. Future Land Uses/Tribal Rights}

Applicable to: Remediation

Source: EPA CERCLA Criterion \#3; ProTech Element \#19.2

Should it be considered by PI in formulating demonstration objectives?: YES

This criterion addresses the degree to which human health and the environment are protected over time at the site of contamination, once actual treatment has been completed. Of interest here is the requirement for continuing monitoring, management and control of the treatment area.

Identification of demonstration objectives

- Demonstration objective regarding the capacity for unrestricted use in and around the contaminated area after treatment

Included, as follows:

Not included, because:

- Demonstration objective regarding the degree of continuing control and monitoring required for the contaminated area and if necessary, the reliability of that long-term control

Included, as follows:

Not included, because: 
WHC - EP - 0777

\section{Criterion 12. Socin..Economic Impacts}

Applicable to: Remediation, Drilling, Characterization and Monitoring

Source: ProTech Information Element \#20

Should it be considered by PI in formulating demonstration objectives?: Possibly.

This criterion addresses the broad socio-economic impacts that might arise with use of the technology. The Technology Assessment Task Team will make a full evaluation of these impacts, but the PI may determine (in conjunction with the ID Technology Acceptance Team) that certain data should be collected during the demonstration to support this assessment.

\section{Identification of demonstration objectives}

- Demonstration objective regarding the economic impacts of using the technology

Included, as follows:

Not included, because:

- Demonstration objective regarding the labor force demands of using the rechnology

Included, as follows:

Not included, because:

\section{Criterion 13. Regulatory Infrastructure Requirements}

Applicable to: Remediation, Drilling, Characterization and Monitoring

Source: EPA CERCLA Criterion \#6; ProTech Element \#21

Should it be considered by PI in formulating demonstration objectives? : YES

This criterion relates to the general regulatory infrastructure that is required to support use of a technology.

Identification of demonstration objectives

- Demonstration objectives regarding the number of regulatory agencies or regulatory programs that will be required to approve of the technology before it can be used and the likelihood of their approval 
Included, as follows:

Not included, because:

- Demonstratior objectives regarding the extent of coordination with regulatory agencies that will be required for use of the technology

Included, as follows:

Not included, because:

\section{Criterion 14. Compliance with Regulatory Requirements}

Applicable to: Remediation, Drilling, Characterization and Monitoring

Source: EPA CERCLA Criterion \#2; ProTech Element \#21

Should it be considered by PI in formulating demonstration objectives?: YES

This criterion addresses whether the technology will meet regulatory standards as it is being demonstrated and deployed. In particular, remediation technology demonstrations should explicitly consider the degree to which the technology is able to meet potentially applicable cleanup standards.

\section{Identification of demonstration objectives}

- For remediation technologies, demonstration objectives regarding ability of the technology to meet probable cleanup standards that would be applied during deployment

Included, as follows:

Not included, because:

- Demonstration objectives regarding the ability of the technology to meet any other applicable chemical-specific regulations, such as emissions standards

Included, as follows:

Not included, because:

- Demonstration objectives regarding the ability of the technology to meet action-specific regulations, such as well construction standards for drilling technologies

Included, as follows:

Not included, because: 
- Demonstration objectives regarding the ability of the technology to meet location-specific regulations

Included, as follows:

Not included, because:

- Demonstration objectives regarding the ability of the technology to meet any other relevant criteria, advisories, and quidance, such as cleanup or other milestones imposed by regulatory agencies

Included, as follows:

Not included, because:

Criterion 15. Overall Protection of Human Health and the Environment

Applicable to: Remediation, Drilling, Characterization and Monitoring

Source: EPA CERCLA Criterion'\#1

Should it be considered by PI in formulating demonstration objectives?: Generally not directly demonstrable, but should be kept in mind as an overarching standard.

As applied to remediation technologies, this criterion reflects CERCLA's statutory mandate to select remedies that protect human health and the environment. In remedy selection, the assessment of protectiveness draws on the assessments conducted under other CERCLA criteria, especially long-term effectiveness and permanence, short-term effectiveness, and compliance with ARARs. As applied to drilling and characterization and monitoring technologies, this criterion is used to make an overall assessment of whether the technology will function in a safe manner that provides adequate protection of human health and the environment. This criterion will in general be assessed by other components of the VOC-Arid ID. Team, and will generally not result in specific demonstration objectives. However, the PI should keep this criterion in mind as an overarching standard for the acceptability of the technology. A technology that does not protect human health and the environment will not be acceptable, no matter how well it may perform in other respects. 
WHC - EP - 0777

ATTACHMENT 3

Environmental Regulatory Checklist 
ENVIRONMENTAL REGULATORY CHECRLIST

Please answer yes or no to all of the following questions, considering both construction and operation. Use a "?" if unsure. Direct any questions or comments to Fred Morris, (206) 5283332 , or Tom Grant, (206) 528 3331, fax (206) 5283552. After completing this checklist, include it in the Conceptual Test Plan as Appendix D.

Project Number and Title

Will the proposed action:

\section{AIR EMISSIONS}

1. Result in gaseous emissions to the ambient air? If yes, describe.

2. Result in particulate emissions (liquid or solid) to the ambient air?

If yes, describe.

3. Result in thermal discharges to the ambient air? If yes, describe.

4. Cause any other atmospheric disturbance? If yes, describe.

5. Result in emissions of radionuclides to the ambient air? If yes, specify the yearly effective dose equivalent to the public (40 CFR Part 61 subpart H) 


\section{DISCHARGES TO WATER}

6. Discharge any substance (or heat) to surface water? If yes, describe.

7. Discharge any substance (or heat) to the ground or to groundwater? If yes, describe.

8. Involve the injection of any substance (or heat) into the ground or groundwater?

If yes, describe.

9. Alter stream flow rates?

If yes, describe.

10. Significantly alter natural evaporation rates of any water body?

If yes, describe.

11. Involve the discharge of dredged or fill material into wetlands or surface water?

If yes, describe.

12. Potentially provide interconnection between aquifers? If yes, describe.

13. Involve the installation of wells?

If yes, describe. 
WHC-EP - 0777

\section{SCLID AND HAZARDOUS WASTE}

14. Generate non hazardous solid waste?

If yes, describe.

15. Generate hazardous waste?

If yes, describe.

16. Involve the treatment, storage, or disposal of hazardous waste?

If yes, describe.

17. Involve the placement of hazardous waste in or upon the land?

If yes, describe.

18. Generate radioactive, $P C B$, or asbestos waste?

If yes, describe.

\section{LAND USE AND GENERAL}

19. Cause erosion?
If yes, describe.

20. Require excavations?

If yes, describe. 


\section{WHC - EP - 0777}

21. Has any NEPA documentation been initiated? If yes, describe.

22. Use pesticides, carcinogens, or toxic chemicals? If yes, identify.

23. Expose workers to radiation above background levels? If yes, explain.

24. Increase noise level?

If yes, explain.

Signed

Title

\section{Date}

Phone

Address 
WHC - EP - 0777

\section{ATTACHMENT 4}

Conceptual Test Plan Template 


\section{CONTENTS}

1.0 INTRODUCTION

1.1 Purpose and scope

1.2 Background

1.3 Site setting

2.0 TECHNOLOGY DESCRIPTION

3.0 DEMONSTRATION OBJECTIVES AND PARAMETERS

3.1 Sampling and Analytical Procedures

4.0 REGULATORY COMPLIANCE

5.0 DESCRIPTTON OF TASKS AND PROCEDURES

6.0 SITE SERVICES REQIIIREMENTS

7.0 DEMONSTRATION SCHEDULE

8.0 REFERENCES

Appendix A ProTech Profile

Appendix B Demonstration Objectives Worksheet

Appendix C Environmental Regulatory Checklist

Appendix D Procedures (too lengthy to fit into section 5.0) 


\section{CONCEPTUAL TEST PLAN TEMPLATE}

NOTE: Follow the template structure as closely as possible. However, sections may be added or expanded as needed to include all relevant information. All sections of the template must be addressed, even if to identify that the PI does not believe that the section applies to their demonstration.

\subsection{INTRODUCTION}

\subsection{Purpose and scope}

Describe the purpose and scope of the demonstration. Also describe the relationship of the demonstration to Environmental Remediation (ER) needs, activities, and plans.

\subsection{Background}

Include a brief introduction and background of the technoliogy. Briefly describe the baseline technology that will be used for comparison.

\section{3 site setting}

If known, provide a description of the specific site where the technology will be demonstrated. Also, briefly describe the nature and extent of contamination at the site of the demonstration.

\subsection{TECHNOJOGY DESCRIPTION}

Describe in detail the theory on which the technology is based. Provide a complete description of the equipment with appropriate details about size, process design data, monitoring and sampling port locations, etc. Provide a process flow diagram (as appropriate for the technology) identifying conditions at each step including all effluents and residuals produced. Explain how the technology interfaces with other elements of an environmental restoration system.

This information is needed to: (1) ensure proper coordination with existing systems and determine field engineering requirements; (2) ensure regulatory compliance; and (3) obtain safety approval for demonstration.

\subsection{DEMONSTRATION OBJECTIVES AND PARAMETERS}

This section must contain the objectives formulated by the PI from the Objectives Worksheet in Attachment 1 of this preparation guide, plus any other objectives that the PI feels are relevant to the demonstration. The complete objectives worksheet must also be placed in Appendix $B$ of the Conceptual Test Plan.

Demonstration parameters are the specific variables whose values will be measured in specified units during the demonstration. 
The parameters must describe what measurements will be taken during the demonstration to determine that the objectives have been accomplished. Define demonstration parameters for each of the specified objectives. Shown below is an example of the format and content of the parameters and objectives to be included in this section.

Objective 1. Determine the ability of the system to resist fouling.

Parameters: The membrane and system fouling will be determined by measuring the VOC concentration of the various gas streams. The following is a list of the gas samples to be collected (in this case a figure would be used to show were the gas streams are located in the system).

- Gas Composition of System Inlet (SI)

- Gas Composition of Membrane Feed (S2)

- Gas Composition of System Exhaust (S3)

- Gas Composition of Membrane Permeate (S4)

The samples will be taken every $24 \mathrm{~h}$ (as a minimum) and analyzed using a Tri-Odyssey 2001-5 Radical Chloride Unit (a trademark of Transducer Research Inc. [TRI], Naperville, Illinois) every $24 \mathrm{~h}$.

When the removal is in a decreasing trend mode by statistical process control analysis and a trend is not observed in the feed concentration it can be assumed that the membrane is fouling. A change of greater that $5 \%$ will be considered unacceptable.

Objective 2. Determine power consumption

Parameters: Measurement of the power consumption of the skid will be made using a wattmeter totalizer designed to measure the input power for the system.

Objective 3. Evaluate the mechanical durability of the system over a three month period

Parameters: The system is set up to require no maintenance during the three month period of operation. If the system fails or requires any mainteriance during that time the cause and remedy will be recorded.

Objective 4. Evaluate the ability to interface the PAWS sensor system with the CPT system and achieve full operation. 
Parameters: The amount of time it takes to hook up the PAWS system to the CPT will be recorded. The number of changes necessary to speed up the process of hooking up the PAWS system to the CPT will also be recorded.

Again, note that evaluating certain criteria may require gathering data on parameters that are not directly measurable during the demonstration. In these cases the PI should provide some indication of where the additional data would be found outside of the demonstration procedure.

\subsection{Sampling and Analytical Procedures}

Describe sampling and analytical procedures for measuring each of the demonstration parameters identified in section 3.0 that involve sampling and analysis. Analytical methods should be considered and selected in the Data Quality Objective process. This is important to insure that there are no inconsistencies between the level of data quality being utilized during demonstration and the level of data quality necessary to provide conclusive evidence to meet the demonstration objectives. The PI may want to consult EPA's, Data Quality Objectives for Remedial Response Activities: Development Process, EPA/540/G-87/003, Appendices A - C for guidance, on data sampling procedures, statistical, and analytical considerations that go into establishing data quality.

At a minimum, the PI should consider and specify (as appropriate) such data quality attributes as:

- Detection Level

- Precision

- Representativeness

- Accuracy

- Completeness

- Comparability

\subsection{REGULATORY COMPLIANCE}

The only requirement for this section is to reference the Environmental Regulatory Checklist in Appendix C.

\subsection{DESCRIPTION OF TASRS AND. PROCEDURES}

Provide a narrative description of demonstration tasks. Provide detailed procedures covering each aspect of the demonstration. If the procedures are too lengthy for this section please included the details in Appendix $D$ of the Conceptual Test Plan.

This information is needed to ensure that demonstration activities will be properly conducted as required by the PI. Use of procedures will ensure that the demonstration is conducted safely. This information is required to obtain quality assurance and safety approvals for demonstration. 


\subsection{SITE SERVICES REQUIREMENTS}

Provide a listing of utilities requirements, site access requirements, and site preparation requirements. Also include housing/storage requirements and transportation requirements. Provide description of all personnel and equipment support the PI is anticipating will be supplied by Demonstration Operations.

This information is needed by Demonstration Operations to ensure that site services and equipment will be available to meet the needs of the Principal Investigator. This information will eliminate any confusion over what the PI is providing, and what is being provided by Demonstration Operations.

\subsection{DEMONSTRATION SCHEDULE}

Complete a schedule identifying all demonstration activities, including the completion of all documentation, demonstration execution, and post-demonstration activities.

This information is needed by Demonstration Operations to schedule resources to conduct demonstrations. This information will also be used to ensure that sufficient time is allotted for regulatory and Hanford compliance issues.

\subsection{REFERENCES}

Include all references used in the Conceptual Test Plan in this section.

\section{Appendix A ProTech Profile}

Include the completed ProTech Profile from Attachment 1 of this preparation guide in this Appendix.

\section{Appendix B Demonstration Objectives Worksheet}

Include the completed Objectives Worksheet from Attachment 2 of this preparation guide in this Appendix.

\section{Appendix C Environmental Regulatory Checklist}

Include the completed Environmental Regulatory Checklist from Attachment 3 of this preparation guide in this appendix.

\section{Appendix D}

Any procedures that may be too lengthy to fit into section 5.0 should be included in this Appendix. 
WHC - EP - 0777

ATTACHMENT 5

Integrated Test Plan Template 
WHC-EP - 0777

CONTENTS

\section{INTEGRATED TEST PLAN TEMPLATE}

1.0 INTRODUCTION

1.1 Purpose and Scope

1.2 Background

1.3 Site setting

2.0 TECHNOLOGY DESCRIPTION

3.0 DEMONSTRATION OBJECTIVES AND PARAMETERS

3.1 Sampling and Analytical Procedures

4.0 REGULATORY COMPLIANCE

4.1 Overview of System Residuals

4.2 NEPA

4.3 CERCLA

4.4 RCRA

4.5 Washington Administrative Code

4.6 Cultural Resources Review

5.0 HANFORD COMPLIANCE

4.1 Safety

4.2 Quality Assurance

4.3 Training

6.0 ORGANIZATION AND RESPONSIBILITIES

6.1 Demonstration Operations

6.2 Project Engineer

6.3 Field Team Leader

6.4 Principle Investigator

6.5 Site safety officer

7.0 DESCRIPTION OF TASKS AND PROCEDURES

8.0 SITE SERVICES REQUIREMENTS

9.0 DEMONSTRATION SCHEDULE

10.0 REFERENCES

Appendix A Procedures (too lengthy for section 7.0)

\section{FIGURES :}

1. Hanford Site Map (Hanford Site shown in Washington with an enlargement showing the major Areas, i.e. 200 West, 200

East, 300 Area, etc.) A similar map should be provided if the demonstration site is not Hanford.

2. More detailed site maps if appropriate

3. Other figures such as well construction diagrams, process flow diagrams, design drawings, etc.

4. Field Demonstration Organization

$$
\text { Att } 5-i
$$




\section{INTEGRATED TEST PLAN TEMPLATE}

The Integrated Test Plan will be produced by Demonstration Operations with assistance from the PI. Follow the template structure as closely as possible. However, sections may be added or expanded as needed to include all relevant information.

\subsection{INTRODUCTION}

\subsection{Purpose and scope}

Same as the Final Conceptual Test Plan (Attachment 4)

1.2 Background

Same as the Final Conceptual Test Plan (Attachment 4)

\subsection{Site setting}

Expanded from the Final Conceptual Test Plan to include site details (Attachment 4)

\subsection{TECHNOLOGY DESCRIPTION}

Same as the Final Conceptual Test Plan (Attachment 4)

\subsection{DEMONSTRATION OBJECTIVES AND PARAMETERS}

Same as the Final Conceptual Test Plan (Attachment 4)

3.1 Demonstration objectives

Same as the Final Conceptual Test Plan (Attachment 4)

3.2 Demonstration Parameters

Same as the Final Conceptual Test Plan (Attachment 4)

3.3 Sampling and Analytical procedures

Same as the Final Conceptual Test Plan (Attachment 4)

\subsection{REGULATORY COMPLIANCE}

Prepare the Regulatory Compliance Section using the following sections. Contact the Demonstration Operations Manager for an example of these sections. As soon as this section is completed it must be sent to the VOC-Arid ID regulatory review group at Battelle Seattle. The Demonstration Operations Manager will be able to supply the name and phone number of this contact in seattle.

\subsection{Overview of System Residuals}

4.2 National Environmental Policy Act (NEPA)

4.3 CERCLA 


\subsection{RCRA}

\subsection{Washington Administrative Code}

\subsection{Cultural Resources Review}

A Cultural Resources Review will need to be completed for intrusive demonstrations if one has not been conducted on the site for past activities. Reference the review number and any other pertinent information pertaining to the Cultural Resources review.

\section{0 HANFORD COMPLIANCE}

This section identifies Hanford compliance areas for this field demonstration. It should be written using the following sections.

\section{1 safety}

List the Hazardous Waste Operation Plan for the demonstration site and any other pertinent safety information.

\subsection{Quality Assurance}

Cite all WHC QA documents, DOE orders, and other QA documents that pertain to $Q A$ for this demonstration.

\subsection{Training}

List the training required for each task of the demonstration.

\subsection{Organization and Responsibilities}

This section should follow the format and content of the example below.

Example starts here.

The field demonstration will be performed by Demonstration Operations working with the principal investigator (Figure General organization and responsibilities for the VOC-Arid TD. Demonstration Operations and the ERA can be found in their respective Project Management Plans. Organization for the field demonstration is shown in Figure. The following sections contain a description of responsibilities for field demonstrations. 
WHC - EP - 0777

Figure _- Field Demonstration Organization Chart

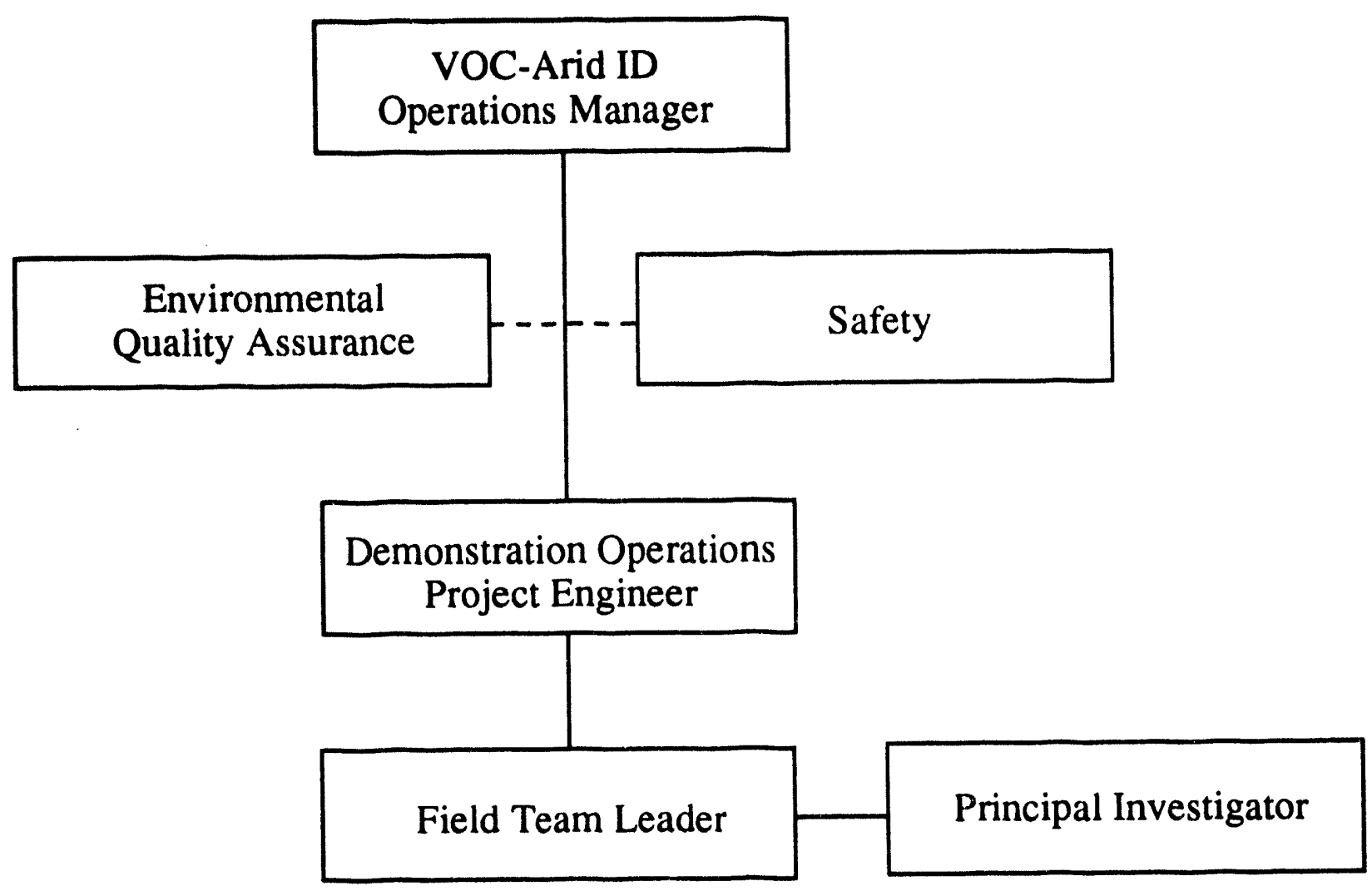




\subsection{Demonstration Operations}

Demonstration operations is responsible for site characterization, engineering and conduct of field demonstrations. Demonstration operations ensures regulatory and DOE/Hanford compliance for field demonstrations.

\subsection{Profect Engineer}

The project engineer is responsible for coordinating with the principal investigators and the field team leaders and ensuring the availability of needed equipment and materials.

\subsection{Field Team Leader}

The field team leader is responsible for overall technical field management of the project and control of site access. All onsite personnel report through the on site field team leader to accomplish their work.

\subsection{Principal Investigator}

The principal investigator will:

- ensure that the objectives of the demonstration are met

- conduct the demonstration through coordination with the field team leader

- provide all monitoring equipment to be demonstrated

- provide personnel to set up the equipment, perform the demonstration, and analyze the results

- prepare a performance evaluation report that reviews the results of the demonstration related to each objective.

\subsection{Site Safety Officer}

The site safety officer is responsible for the generation of the Hazardous Waste Operating Permit (HWOP). The site safety officer has the final authority with regard to safety in the field.

Although personnel onsite are obligated to conduct activities in a safe and professional manner, the site safety officer is ultimately responsible for correcting any unsafe condition that may arise during field operations.

\subsection{DESCRIPTION OF TASKS AND PROCEDURES}

Same as the Final Conceptual Test Plan (Attachment 4)

\subsection{SITE SERVICES REQUIREMENTS}

Same as the Final Conceptual Test Plan (Attachment 4) 


\subsection{DEMONSTRATION SCHEDULE}

Same as the Conceptual Test Plan, except modified to reflect any changes in schedule. This schedule should identify all demonstration activities, including the completion of all documentation, demonstration execution, and post-demonstration activities.

\subsection{REFERENCES}

Include all references in this section. 
WHC - EP - 0777

\section{ATTACHMENT 6}

フ

Performance Evaluation Report Template 


\section{PERFORMANCE EVALUATION REPORT TEMPLATE}

CONTENTS

EXECUTIVE SUMMARY

\subsection{INTRODUCTION \\ 1.1 Purpose and Scope \\ 1.2 Background \\ 1.3 Site setting}

2.0 TECHNOLOGY AND PROCESS DESCRIPTION

3.0 DEMONSTRATION OBJECTIVES AND PARAMETERS 3.1 Description of Tasks and Procedures

3.2 Sampling and Analytical Procedures

4.0 OPERATIONS DOCUMENTATION

4.1 Operational History

4.2 Summary of Operating Conditions

5.0 PERFORMANCE DATA AND EVALUATION

6.0 CONCLUSIONS AND LESSONS

7.0 REFERENCES

Appendix A Revised ProTech Profile

Add other appendices as needed 
The following is an outline for preparing Performance Evaluation Reports. Follow the template as closely as possible. However, sections may be added or expanded as needed to include all relevant information.

Many of the sections in this report are the same as the Integrated Test Plan and may simply be copied to the Performance Evaluation Report.

\section{EXECUTIVE SUMMARY}

Summarize the demonstration objectives, the quantitative and qualitative results, and conclusions regarding the performance of the demonstrated technology.

\subsection{INTRODUCTION}

\subsection{Purpose and scope}

Same as the Integrated Test Flan.

\subsection{Background}

Same as the Integrated Test Plan, except add a paragraph describing how, when, and for how long the demonstration was conducted.

\subsection{Site setting}

Use the information in the Integrated Test Plan and improve on it as follows. Describe specifically the layout of the site, identify the location of demonstration activities at the site, and provide a detailed schematic of the process and its relationship to other site operations.

\subsection{TECHNOLOGY AND PROCESS DESCRIPTION}

Same as the Integrated Test Plan (Attachment 5).

\subsection{DEMONSTRATION OBJECTIVES AND PARAMETERS}

Same as the Integrated Test Plan (Attachment 5).

\subsection{Description of Tasks and Procedures}

Reference the Integrated Test. Plan (Attachment 5).

\subsection{Sampling and Analytical procedures}

Same as the Integrated Test Plan (Attachment 5). 
WHC - EP - 0777

\subsection{OPERATIONS DOCUMENTATION}

This section can be included here or attached as an appendix.

\subsection{Operational History}

Provide a chronological log of the demonstration activities and results.

\subsection{Sumary of Operating Conditions}

Briefly describe operating conditions, weather, and any other pertinent parameters, preferably in tabular form by date.

\subsection{PERFORMANCE DATA AND EVALUATION}

The primary objective of the demonstration is to evaluate the performance of the technology against the baseline. Detail the quantitative and qualitative results of the demonstration relative to the baseline. Did the technology meet demonstration objectives? If so, how and how well?

If appropriate, this chapter can begin with a presentation of the direct demonstration parameter data collected. Following that, the chapter should be subdivided into sections that address each of the specified demonstration objectives that can be measured by the demonstration results. These sections should include a discussion of whether and how the demonstration findings (the collected data) support the demonstration objective and prove that the technology meets the specified criteria.

Finally, the PI should discuss the performance of the technology relative to those demonstration objectives that are key to technology evaluation, but that cannot be fully evaluated based on direct demonstration data collection (i.e., because they are dependent on information collected outside of the demonstration). In this case, the PI can draw from other data sources or from best professional judgement to make the best assessment of the technology relative to the objective. The PI should provide references for any information provided, and indicate what further information might be required to more fully answer the demonstration objective.

\subsection{CONCLUSIONS AND LESSONS}

Summarize the demonstration results relative to the objectives of the demonstration. Provide recommendations regarding the status of the technology. In other words, does performance relative to demonstration objectives support a decision to move forward with immediate technology transfer and deployment? Is further demonstrating required? 
Summarize operational lessons learned. These lessons generally relate to set-up and shakedown experiences, scale-up, day-to-day problems, institutional issues, and the like. The PI and Project Engineer/Scientist assigned from Demonstration Operations are responsible for summarizing these immediately following the demonstration.

\subsection{REFERENCES}

Include all references in this section.

\section{Appendix A Revised Protech Profile}

At the time the Performance Evaluation Report is prepared, the ProTech Profile needs to be updated. A hard copy of the revised ProTech Profile must be attached as Appendix A to the Performance Evaluation Report, and an electronic copy should be forwarded to the ProTech Point Person. Contact Demonstration Operations for the location of the Point Person.

fdd other appendices as needed 

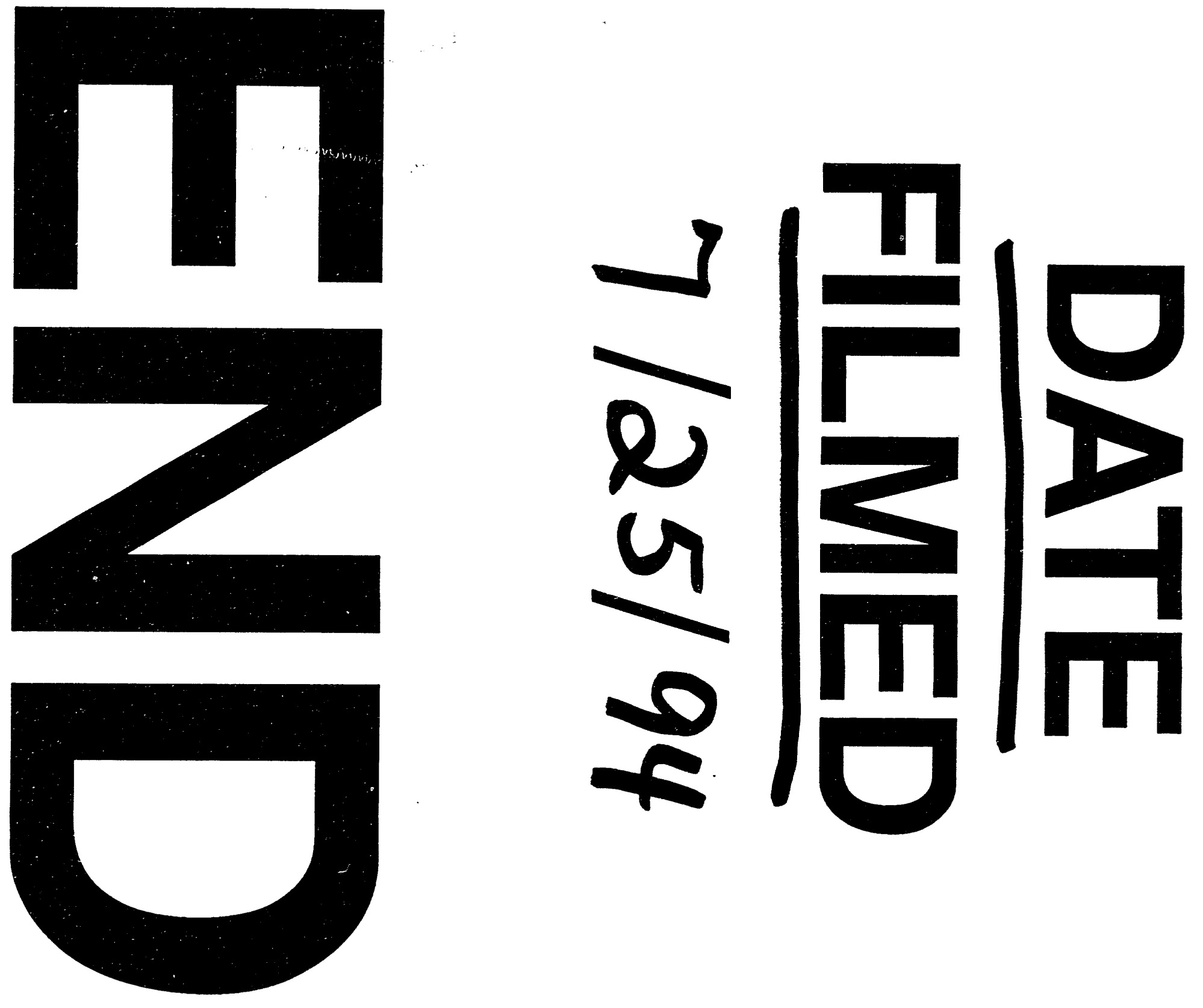
